\title{
Exploring Predictability Of Instructor Ratings Using A Quantitative Tool For Evaluating Soft Skills Among MBA Students
}

Robert T. Brill, Moravian College, USA

David M. Gilfoil, DeSales University, USA

Kristen Doll, Moravian College, USA

\begin{abstract}
Academic researchers have often touted the growing importance of "soft skills" for modern day business leaders, especially leadership and communication skills. Despite this growing interest and attention, relatively little work has been done to develop and validate tools to assess soft skills. Forty graduate students from nine MBA courses completed the McCann Soft Skills Assessment Tool - a paper-pencil test designed to measure leadership, teamwork, critical thinking, logical reasoning, communication, and holistic thinking. These students were also rated by their instructors on the same six dimensions in an attempt to validate the soft skills instrument. Results showed significant correlations between leadership and communication assessment scores and faculty ratings of students on the same dimensions; however none of the other four soft skill dimensions were empirically validated. Data also indicated moderate test - retest reliability for the assessment tool. While some limitations are acknowledged in the current study, findings suggest that further refinement and empirical validation of the McCann Soft Skills Assessment Tool can better aid practitioners in understanding and developing these important dimensions of business competency.
\end{abstract}

Keywords: Soft Skills Assessment; MBA Students; McCann Soft Skills Assessment Tool; Faculty Ratings of Students

\section{INTRODUCTION}

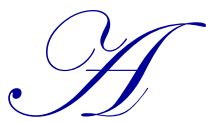

s one looks out upon the ever changing and increasingly complex global landscape of business and industry, it becomes more and more apparent that innovations and problem-solving will require multi-disciplinary teams engaging in highly intense collaboration. As such, the emphasis on greater knowledge and technical skills as a key asset, will need to be complemented with refined soft skills (specifically, leadership, teamwork, critical and holistic thinking, logical reasoning, and communication skills) to allow the proper expression, implementation, and collaboration for optimal use of knowledge assets. Chakraborty (2009) made a compelling argument for the essential role of soft skills in formulating well-rounded individuals who will be the key constituents in successfully navigating the change with which we are confronted. Those constituents begin with students and educators, as well as their institutions; but also extend to society, in general, with the vested interest in advancing progress in a manner "to revive the falling standards of values and ethics and also by incorporating the right mix of domain knowledge and soft skills quotient" (Chakraborty, 2009, p. 16).

The call for greater attention to soft skills development has been trumpeted in a number of disciplines, particularly business management (Mitchell, Skinner, \& White, 2010; Rangnekar, 2011) and information systems/technology (Beard, Schwieger, \& Surendran, 2008; Joseph, Ang, Chang, \& Slaughter, 2010). Collectively, these authors suggest that soft skills are greatly desired by employers, yet are elusive in many of these disciplines' 
contemporary models of pedagogy, and have not been sufficiently explored due to great difficulty in capturing them through systems of outcomes assessment. This last point may be the key to understanding where better solutions for nurturing soft skills within higher education begins - with a reliable and valid assessment tool. Not only is such a tool lacking within higher education teaching - learning cycles, but also in the training industry where a surge of elearning platforms targeting the development of soft skills among trainees exists (Roberts, 2008). As the measurement challenge continues, the demand for soft skills persists.

A recent survey of 276 prospective employers identified the top 12 attributes deemed most important to them (Koncz \& Collins, 2007). Communication skills were at the top of the attributes with teamwork skills coming in at third. Interpersonal, problem-solving and analytic skills were in the middle of the pack capturing fifth through seventh place respectively. Although the prototypical dimension structure for soft skills varies widely, this employer list aligns extremely well with the six soft skill dimensions assessed in the current study, the McCann Business Soft Skills Assessment (Schultz, 2010). The underlying dimension of the McCann tool was founded upon the SCANS (Secretary's Commission on Achieving Necessary Skills; U.S. Department of Labor, 1990) standards, and includes:

1. Leadership - The ability to effectively guide or direct others.

2. Teamwork - The ability to cooperatively and with a coordinated effort work with others to reach a common cause or interest.

3. Critical Thinking - Disciplined thinking that is clear, rational, open-minded, and informed by evidence which helps one to decipher whether a claim is true or false.

4. Logical Reasoning - The ability to determine a conclusion, by applying a rule to a given precondition. The three types of logical reasoning include deduction, induction, and abduction.

5. Communication Skills - the ability to convey thoughts, opinions, and information to others. This can include speech, writing, or signs.

6. Holistic Thinking - The ability to recognize the larger picture and understand the interrelationship between the parts and the whole.

Working in collaboration with several institutions of higher education, McCann Associates developed and conducted some initial pilot testing resulting in the 36 items instrument (six items per dimension) used in this study. Whereas other studies have typically employed self-report ratings to personalized statements (Kumara \& Sahasranam, 2008), or based items on discipline-specific critical incidents (Joseph et al., 2010), the McCann tool employs generic business scenario questions requiring a correct answer response.

The purpose of the present study was to evaluate the developing tool, McCann Business Soft Skills Assessment Tool, in terms of its predictive validity of instructor ratings of students on its six dimensions: leadership, teamwork, critical thinking, logical reasoning, communication skills, and holistic thinking.

\section{METHOD}

\section{Participants}

Instructors in nine MBA courses were encouraged to promote student participation in the study. A total of 40 students completed the soft skills assessment tool, and 26 of those 40 completed it a second time to assess testretest reliability.

\section{Materials}

Participants were asked to complete an on-line version of the 36 question McCann Business Soft Skills Assessment Tool. The instrument examined six domains (six items per domain) of soft skills: leadership, teamwork, critical thinking, logistic reasoning, communication skills, and holistic thinking. Two forms were used (test/re-test) and counterbalanced for order.

Criterion data was collected from MBA faculty using a rating grid presented to them via SurveyMonkey. Instructors rated individual students on each dimension using the five-point scale indicated below. Grade 
descriptors were based on typical distributions for course grades - with the top anchor, excellent, attempting to allow discrimination among top student achievers in the direction of the skew:

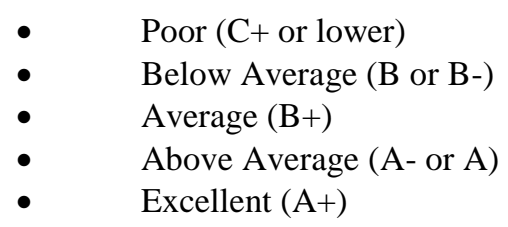

Instructors were also permitted to record a Not Applicable option if they felt there was not enough behavioral evidence to provide a reliable rating.

\section{Procedure}

Participating graduate students completed and returned consent forms to class instructors who forwarded them to researchers. The consent forms also included permission for instructors to submit to the researcher confidential ratings of the student on the soft skill dimensions. Students then received an e-mail from the researcher with a link for the assessment, as well as a username and password to access the instrument. Study participants had one week to complete the online tool within a continuous 75 minute time limit. Demographic data were also collected online during this time.

Students who consented to be rated by their instructors on the soft skills dimensions (100\% consented) were listed in a separate e-mail sent to the instructor toward the end of the course. That e-mail also contained a link to the SurveyMonkey rating forms for each student. Instructors were given definitions of each dimension and directed to evaluate each student.

\section{Results}

The descriptive statistics for the overall McCann Soft Skills Assessment Tool scores, individual dimension scores, and criteria ratings are provided in Table 1. Average ratings tended to come in above the midpoint of the scale, but standard deviations did not indicate any concerns regarding lack of variability in the data. The minimum and maximum values also suggested that, for the most part, the full range of values were being employed within each dimension for both predictors (i.e., test scores) and criteria (i.e., instructor ratings). Based on the 26 subjects who were able to take both forms of the soft skills assessment tool, approximately six weeks apart, test - retest reliability was moderate in strength $(r=0.68, p<.01)$. Typically, a desirable reliability correlation should exceed the threshold of .80 (Dunn, 2001). All reported correlations are Pearson product moment correlation coefficients.

Table 1: Descriptive Statistics for Predictor and Criteria Measures

\begin{tabular}{|l|c|c|c|c|c|}
\hline \multicolumn{1}{|c|}{ Measures } & n & M & SD & Min & Max \\
\hline Predictors (6 point scales) & & & & & \\
\hline Overall Score & 40 & 24.03 & 4.08 & 13 & 31 \\
\hline Leadership Score & 40 & 4.43 & 1.22 & 2 & 6 \\
\hline Teamwork Score & 40 & 4.05 & 1.11 & 1 & 6 \\
\hline Critical Thinking Score & 40 & 3.98 & 0.95 & 2 & 6 \\
\hline Logical Reasoning Score & 40 & 3.48 & 1.28 & 1 & 6 \\
\hline Communication Score & 40 & 3.70 & 0.97 & 1 & 5 \\
\hline Holistic Thinking Score & 40 & 4.35 & 0.89 & 2 & 6 \\
\hline Criteria (5 point scales) & & & & & \\
\hline Leadership Rating & 27 & 3.15 & 0.86 & & \\
\hline Teamwork Rating & 30 & 3.53 & 0.90 & 1 & 4 \\
\hline Critical Thinking Rating & 31 & 3.16 & 1.07 & & 5 \\
\hline Logical Reasoning Rating & 30 & 3.43 & 0.97 & & 5 \\
\hline Communication Rating & 30 & 3.37 & 0.81 & & 1 \\
\hline Holistic Thinking Rating & 31 & 3.39 & 0.80 & 2 & 5 \\
\hline
\end{tabular}


Predictive validity correlations for each predictor - criterion pair within each soft skill dimension are reported in Table 2. The two dimensions to yield significant correlations were leadership $(r=0.52, p<.01)$, and communication $(r=0.54, p<.01)$. The other dimensions did not yield significant correlation between predictor scores and instructor ratings. Although the correlations for teamwork $(r=.25)$ and holistic thinking $(r=.27)$ were moderately positive, the relationship was not strong enough to yield significance at the .05 probability level. Correlations within the critical thinking and logical reasoning dimensions were positive, but very small. To better understand the lack of consistency in significant predictive validity indicators across dimensions, the "soft skills" factor structure was analyzed. More specifically, the degree of independence of each soft skill dimension (within assessment scores and within instructor ratings) was evaluated to investigate the degree to which each measure is able to uniquely distinguish between each of the six soft skill dimensions.

Table 2: Predictive Validity Correlations between Predictor Scores from the Soft Skills Assessment and Criterion Ratings from Course Instructors for each Dimension

\begin{tabular}{|l|c|}
\hline \multicolumn{1}{|c|}{ Dimension } & Correlation \\
\hline 1. Leadership & $.52^{* *}$ \\
\hline 2. Teamwork & .25 \\
\hline 3. Critical Thinking & .07 \\
\hline 4. Logical Reasoning & .14 \\
\hline 5. Communication & $.54 * *$ \\
\hline 6. Holistic Thinking & .27 \\
\hline Note. $* * p<.01$
\end{tabular}

It should be noted, however, that some relatedness between dimensions is expected since they share an underlying commonality reflected in their classification under the "soft skills" umbrella. Similar to Sternberg's "g factor" (general intelligence) often explored in cognitive psychology as an overarching trait underlying different types of intelligence (Sternberg, 2003), there is possibly a similar general personality/social trait in the soft skills arena. It may also be that this general soft skills trait similarly drives correlations between distinctive measures of soft skills aptitude in the way that the $\mathrm{g}$ factor drives small to moderate correlations in the cognitive aptitude space. Recent work exploring co-curricular assessment scale development, suggests that perhaps "emotional intelligence" may be the underlying factor (Feldman, Aper, \& Meredith, 2011). Regardless, to merit effort of quantification, measures of sound psychometric quality should be sufficiently sensitive to reliably distinguish levels of each dimension within individual subjects. Inordinately high correlations between dimensions (i.e., dimensions not being independent of each other) would be a concerning indicator about the measurement source's inability to assess dimensions independently.

The results of inter-dimensional correlations for both sources of soft skill measurements are presented in Table 3. It is clear that the McCann Soft Skills Assessment Tool does a fairly good job at yielding profiles in which dimensions tend to be generally independent of each other. Only three of the fifteen dimensional pairings (i.e., leadership - critical thinking, teamwork - communication and communication - holistic thinking) yield a significant pattern of interrelated scores. This pattern certainly suggests a keener sensitivity to distinguishing between dimensions relative to the pattern that emerges for instructor ratings. Within the instructor ratings of student soft skills, the same analyses indicate not only a high correlation for all fifteen pairs of dimensions, but fourteen of fifteen are significant at the .01 probability level. These high correlation results suggest a commendation for the psychometric properties of the soft skills assessment tool, and may also shed some light on the inconsistencies in the predictive validity outcomes in Table 2 as discussed in the following section.

Table 3: Inter-Dimension Correlations for Both the Predictor Scores (Top Triangle) and Ratings from Course Instructors (Bottom Triangle)

\begin{tabular}{|l|c|c|c|c|c|c|}
\hline \multicolumn{1}{|c|}{ Dimension } & $\mathbf{1}$ & $\mathbf{2}$ & $\mathbf{3}$ & $\mathbf{4}$ & $\mathbf{5}$ & $\mathbf{6}$ \\
\hline 1. Leadership & & .23 & .01 & $.34^{*}$ & .31 & -.02 \\
\hline 2. Teamwork & $.85^{* *}$ & & .20 & .22 & $.42^{* *}$ & .27 \\
\hline 3. Critical Thinking & $.79^{* *}$ & $.64^{* *}$ & & .20 & .19 & .13 \\
\hline 4. Logical Reasoning & $.72^{* *}$ & $.56^{* *}$ & $.81^{* *}$ & & .22 & .23 \\
\hline 5. Communication & $.70^{* *}$ & $.44^{*}$ & $.82^{* *}$ & $.65^{* *}$ & $.48^{* *}$ \\
\hline 6. Holistic Thinking & $.60^{* *}$ & $.49^{* *}$ & $.74^{* *}$ & $.78^{* *}$ & $.66^{* *}$ & \\
\hline
\end{tabular}

Note. $* * p<.01 ; * p<.05$ 


\section{Discussion}

Based on (a) test-retest reliability, (b) the pattern of validity correlations particularly for leadership and communication, (c) the sensitivity in distinguishing respondents (see standard deviations and minimum/maximum values in Table 1), and (d) predominantly independent sub-scores for the predictor dimensions (see Table 3), this pilot study suggests that the McCann Soft Skills Assessment Tool is useful.

\section{Predictive Validity}

The two dimensions identified by many as the most important of the soft skills, leadership and communication, worked particularly well to predict instructor ratings of those students' course performance in those dimensions. It has been asserted by experts in the field of business education that these two soft skill traits may be the most important ones to develop (Mitchell, Skinner, \& White, 2010). Leadership and communication were identified by a sample of business educators as "the most important soft skills for success in the twenty-first century workforce" based on survey results (Mitchell, Skinner, \& White, 2010, p. 52). On the criterion side, these may also be the most reliable ratings (compared to other dimensions) since instructors may have greater opportunity of exposure to such skills by their students, as well as a more concrete frame of reference for the behaviors that constitute these skills. Leadership and communication can be defined and observed in more behavioral terms; whereas logical reasoning, critical thinking, and holistic thinking are more mental/cognitively based. These skills may tend to require a more challenging level of inference and/or more in-depth exposure (to student thought processes) on the part of an evaluator. Although teamwork, like leadership and communication, has a strong behavior-based definition as well, actual team-based experiences may not have been formally implemented or explicitly demonstrated within the courses sampled.

\section{Factor Independence among Soft Skill Dimensions}

The McCann Soft Skills Assessment Tool was much more successful at measuring individual soft skills independent of the other dimensions compared to instructor ratings. Comparing the patterns of inter-dimensional correlations (Table 3) suggests that a "paper-pencil" skills assessment tool may enable a measurement strategy that can isolate a demonstration of the specific soft skill competency without the potential problems that can come from human judgment. The extremely large inter-dimensional correlations within the predictor criteria ratings suggest clear evidence of a "halo bias" contaminant (the strong influence by the instructor's general impression of the student), inhibiting distinction between impressions of the student on each of the dimensions. Excessively high correlations among same source rating dimensions have been well established as a reliable indicator of halo bias (Fisicaro \& Vance, 1994).

In addition, halo bias may be a partial explanation for the inconsistent predictive validities listed in Table 1. If, as suggested by the business educators sampled by Mitchell, Skinner, and White (2010), there is an intuitive sense of importance for communication and leadership as the perceived dominant soft skill competencies, evaluation of students on these two dimensions may be trickling into effect and distort ratings in the other dimensions. This possibility is further supported by the aforementioned assertions about the greater availability of evaluative information for these two dimensions, leadership and communication in a typical classroom environment.

\section{Shortcomings and Limitations}

The current study has limitations that should be noted. First, employing a larger sample size would provide a more powerful study of reliability and predictive validity. Second, subject motivation was hard to assess given that it was an independent on-line administration. However, some concern persists since it was impossible to standardize how the assessment opportunity was introduced and embedded into the course as suggestions for bolstering student motivation and implementation into the course grading structure were left up to the cooperating instructors.

The third, but most significant, concern lies with the large and consistent inter-correlation of (instructor) ratings of students suggesting some possible contamination of the criteria measures based on halo bias. Although 
research has indicated that some "true halo" may exist (i.e., in contrast to halo bias) given common inter-relatedness of the actual performance dimensions (Goffin, Jelley, \& Wagner, 2003), the inter-correlations demonstrated among performance ratings by instructors seem extreme in this study.

\section{Future Directions}

To realize greater potential of the McCann tool, and despite concerns with current criteria measures, evidence suggests that further piloting would be worthwhile, as well as some possible guidance on which dimensions may need refinement. In particular, holistic thinking tended to have a high average and low standard deviation among respondents relative to the other dimensions collectively. This may suggest some concern for the dimension's sensitivity toward individual differences on that construct. Also, teamwork seems to remain an elusive construct to capture in the context of a quantitative inventory as opposed to more traditional behavior-based ratings (Dickinson \& McIntyre, 1997), although the uncertain accuracy of instructor ratings on teamwork leaves this unclear.

Future development and refinement should include validation with more authentic sources of "soft skill" student learning outcomes (Banta, Lund, Black, \& Oblander, 1996; Janesick, 2006). Future studies should also consider more sophisticated rubrics to guide subjective rating systems (Beard et al., 2008). Authentic assessments have been defined as "the real application of a skill beyond its instructional context . . . requiring students to apply what they have learned" (Mertler, 2003, pp. 10-11). This learning typically takes place in a real world type of scenario. Authentic course-embedded assessments are very difficult and time consuming to implement, but their cost-benefits should be carefully weighed in terms of assessment system quality and pedagogical improvement potential.

\section{CONCLUSION}

Still an evolving area of study, many myths exist that oversimplify soft skills in terms narrowing their multifaceted nature and entrenching them as purely inborn traits (Rao, 2012). A measure like the McCann Soft Skills Assessment Tool can go a long way to debunking those myths and properly illustrating these important business competencies. As mentioned, there is also a growing call for greater attention to soft skills development in academia and global industry which further drives the need for web-based and e-learning platforms with sound pedagogical practices to advance soft skills (Morgan \& Adams, 2009). As with any sound teaching-learning dynamic, systems will require reliable and valid assessments to provide formative and summative feedback for ongoing improvement and standards accountability. A quantitative objective assessment of soft skills will be a valuable tool for these advances, and evidence suggests the McCann Soft Skills Assessment Tool has the potential to eventually serve this purpose.

\section{AUTHOR INFORMATION}

Robert T. Brill, Ph.D., is Associate Professor of Psychology at Moravian College, USA. He holds a B.A. from LaSalle University, M.S. and Ph.D. from Virginia Polytechnic Institute and State University. His primary areas of research are personal and organizational approaches to work-family/life challenges, optimizing person-job fit through selection, appraisal, training or job redesign; motivation and organizational development; spirituality and the workplace; retention and turnover among nurses. E-mail: brillr@moravian.edu

David Gilfoil, Ph.D., is an Associate Professor and Director of the MBA Program at DeSales University in Center Valley, PA. He holds a B.A. degree in Psychology from the University of Massachusetts, and an M.A. in Cognitive/Experimental Psychology from the College of William and Mary. He received his Ph.D. in Management Science from Stevens Institute of Technology in Hoboken, NJ. E-mail: david.gilfoil@desales.edu (Corresponding author)

Kristen Doll contributed as an undergraduate student researcher at Moravian College. She is currently pursuing a graduate degree in Counseling at Seton Hall University. 


\section{ACKNOWLEDGEMENT}

The researchers are grateful to McCann Associates (Yardley, PA) for the use of their instrument and support in data analysis.

\section{REFERENCES}

1. Banta, W. T., Lund, P. J., Black, E. K., \& Oblander, W. K. (1996). Assessment in practice: Putting principles to work on college campuses. San Francisco: Jossey-Bass Publishers.

2. Beard, D., Schwieger, D., \& Surendran, K. (2008). Integrating soft skills assessment through university, college, and programmatic efforts at an AACSB accredited institution. Journal of Informational Systems Education, 19(2), 229-240.

3. Chakraborty, M. (2009). Soft skills: Essential for shaping well-rounded individuals. Journal of Soft Skills, $3(2), 13-18$.

4. Dickinson, T. L., \& McIntyre, R. M. (1997). A conceptual framework for teamwork measurement. In M. T. Brannik, E. Salas, \& C. W. Prince (Eds.) Team performance, assessment and measurement: Theory, methods, and applications. Mahwah, NJ: Lawrence Erlbaum Associates.

5. Dunn, D. S. (2001). Statistics and data analysis for the behavioral sciences. Boston, MA: McGraw-Hill Publishers.

6. Feldman, M., Aper, J. P., \& Meredith, S. T. (2011). Co-curricular assessment scale development. The Journal of General Education, 60(1), 16-42. doi: 10.1353/jge.2011.0001

7. Fisicaro, S. A., \& Vance, R. S. (1994). Comments on the measurement of halo. Educational and Psychological Measurement, 54(2), 366-371. doi: 10.1177/0013164494054002010

8. Goffin, R. D., Jelley, R. B., \& Wagner, S. H. (2003). Is halo helpful? Effects of inducing halo on performance rating accuracy. Social Behavior and Personality, 31(6), 625-636.

9. Janesick, V. J. (2006). Authentic assessment. New York: Peter Lang Publishing.

10. Joseph, D., Ang, S., Chang, L. H. R., \& Slaughter, A. S. (2010, February.) Practical intelligence in IT: Assessing soft skills of IT professionals. Communications of the ACM, 53(2), 149-154. doi: $10.1145 / 1646353.1646391$

11. Koncz, A., \& Collins, M. (2007). Employers cite communication skills, honesty/integrity as key for job candidates (press release). Bethlehem, PA: National Association of Colleges and Employers.

12. Kumara, V. A. S., \& Sahascanam, C. (2008). An empirical study on students' soft skills inventory test: Reliability and non-parametric analysis. Journal of Soft Skills, 2(3), 35-45.

13. Mertler, C. A. (2003). Classroom assessment: A practical guide for educators. Los Angeles, CA: Pyrczak Publishing.

14. Mitchell, W. G., Skinner, B. L., \& White, J. B. (2010). Essential soft skills for success in the twenty-first century workforce as perceived by business educators. The Delta Pi Epsilon Journal, 52(1), 43-53.

15. Morgan, G., \& Adams, J. (2009). Pedagogy first: Making web-technologies work for soft skills development in leadership and management education. Journal of Interactive Learning Research, 20(2), 129-155.

16. Rangnekar, S. S. (2011, October-2012, March). Soft skills in management. International Journal of Business Insights \& Transformation, 5(1), 108-109.

17. Rao, M. S. (2012). Myths and truths about soft skills. Training and Development, 48-51.

18. Roberts, B. (2008, January). Hard facts about soft-skills e-learning: Companies are increasing their use of the web for management and other training. HR Magazine, 76-78.

19. Schultz. (2010). McCann Business Soft Skills Assessment.

20. Sternberg, R. (2003). Intelligence. In I. B. Weiner \& D. K. Freedheim (Eds.), Comprehensive handbook of psychology, 1, pp. 135-156). New York: Wiley.

21. U.S. Dept. of Labor (1990). Identifying necessary job skills. Retrieved from http://wdr.doleta.gov/SCANS/injs/ 
NOTES 